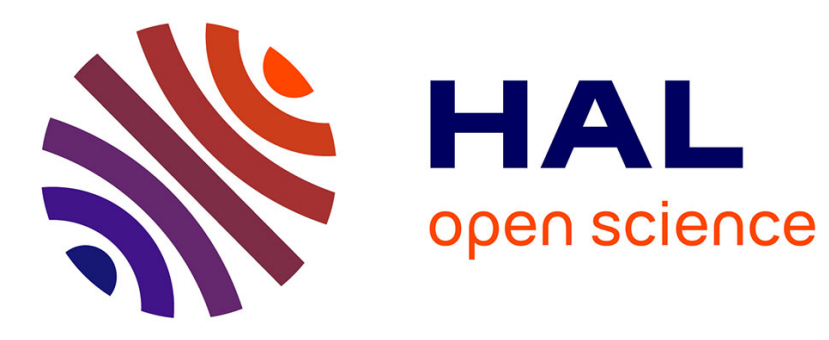

\title{
Integration of Gold Nanoparticles to Modulate the Ignitability of Nanothermite Films
}

Baptiste Julien, Jérémy Cure, Ludovic Salvagnac, Claudie Josse, Alain Estève, Carole Rossi

\section{- To cite this version:}

Baptiste Julien, Jérémy Cure, Ludovic Salvagnac, Claudie Josse, Alain Estève, et al.. Integration of Gold Nanoparticles to Modulate the Ignitability of Nanothermite Films. ACS Applied Nano Materials, 2020, 3 (3), pp.2562-2572. 10.1021/acsanm.9b02619 . hal-02490682

\section{HAL Id: hal-02490682 \\ https://hal.science/hal-02490682}

Submitted on 25 Feb 2020

HAL is a multi-disciplinary open access archive for the deposit and dissemination of scientific research documents, whether they are published or not. The documents may come from teaching and research institutions in France or abroad, or from public or private research centers.
L'archive ouverte pluridisciplinaire HAL, est destinée au dépôt et à la diffusion de documents scientifiques de niveau recherche, publiés ou non, émanant des établissements d'enseignement et de recherche français ou étrangers, des laboratoires publics ou privés. 


\title{
Integration of Gold Nanoparticles to Modulate the Ignitability of
} Nanothermite Films

Baptiste Julien ${ }^{1}$, Jeremy Cure ${ }^{1}$, Ludovic Salvagnac ${ }^{1}$, Claudie Josse $^{2}$, Alain Esteve ${ }^{1}$, Carole $\operatorname{Rossi}^{1, *}$

${ }^{1}$ LAAS-CNRS, University of Toulouse, 7 Avenue du colonel Roche, 31077 Toulouse, France

${ }^{2}$ Centre de Microcaractérisation Raimond CASTAING, 3 rue Caroline Aigle, 31400 Toulouse, France

KEYWORDS: energetic materials, $\mathrm{CuO}, \mathrm{Al}$, STEM-EELS, Thermite multilayered films

\begin{abstract}
:
Thermite multilayered films composed of alternating thin layers of metal/oxidizers have various uses in microelectromechanical systems (MEMS), microelectronics and materials bonding applications. Recently, applied research especially on the micro-initiator applications has engendered an urgent need to improve ignitability without changing the layering, reactant spacing that both affect the combustion characteristics. This work describes an innovative nanoengineering solution to reduce the energy barriers for mass transport making it possible to substantially lower ignition energy of $\mathrm{CuO} / \mathrm{Al}$ reactive multilayers without manipulating the fuel and oxide layers thickness. To that end, gold nanoparticles exhibiting high thermal diffusivity properties are in-situ grown uniformly inside the first $\mathrm{CuO}$ layer to produce localized hot-spots
\end{abstract}


and promote the $\mathrm{Al}+\mathrm{CuO}$ reaction. The $\mathrm{CuO} / \mathrm{Al}$ reactive films with embedded gold nanoparticles exhibit earlier and optimized reaction than standard ones. The effect of gold nanoparticles on the thermite ignition mechanisms and the detailed reaction pathways were characterized by a host of characterization techniques including microscopy, thermal analysis, spectroscopy and X-ray diffractometric. Altogether, results show that the gold nanoparticles are seeding nodular defects with conical shapes provoking - under thermal stimulation- high stressed zones in the multilayer where the $\mathrm{Al}+\mathrm{CuO}$ reaction is quickly triggered. The analysis of reaction products showed that the multilayers break the unreacted $\mathrm{Al}$ droplets early allowing them to burn into the environment. The results provide a behavioral baseline for future studies of interface engineering to tune internal stress-induced reaction in reactive thin films at large.

\section{Introduction}

Nanothermites have received increasing interest over the last two decades for additives in propellants, ${ }^{1,2}$ combustion synthesis of advanced materials ${ }^{3-5}$ and on chips energetics. ${ }^{6-10}$ Different nanothermite systems were produced by different approaches including ball-milling, vapor deposition technique to produce nanopowders mixtures, ${ }^{2,11-15}$ core-shell structure and nanofoils. ${ }^{18-}$

${ }^{22}$ Among them, fully-dense $\mathrm{Al} / \mathrm{CuO}$ multilayer materials represent an interesting system for both its potential applications and fundamental science perspectives. The former has spanned various areas including tunable initiation of secondary explosives, ${ }^{7,23,24}$ joining, brazing and sealing. ${ }^{25}$ The latter has particularly aimed at taking advantage of the fact that these materials offer a unique setting for analysing phase and structure transformations under external stimulation to understand the physics and chemistry involved in reaction processes. It is now well-admitted that the energetic properties of $\mathrm{Al} / \mathrm{CuO}$ multilayer films are mainly governed by the mass transport and diffusion distance between reactant layers influencing both the combustion properties and materials 
ignitability and sensitivity. ${ }^{26-28}$ Three ways were explored in the literature to tailor the thermite multilayers reaction onset and reaction rate release: i) changing the reactant spacing and stoichiometry to affect the reaction kinetics and enthalpy, ${ }^{29}$ or ii) changing the reactant nature, which induces a modification of the final oxide, directly impacting the oxygen diffusion. ${ }^{30}$ But it also modifies the reaction products (sub-oxides in condensed and gaseous phase); or iii) engineering the interfacial layer to produce a more or less porous barrier for the oxygen to diffuse through. ${ }^{31-33}$

In parallel, applied research on micro initiator based applications has engendered an urgent need to improve ignitability, i.e. moderate ignition energy of the thermite film (energy needed to trigger the $\mathrm{Al}+\mathrm{CuO}$ reaction by Joule effect, i.e. thermal initiation), without changing the layering, reactant spacing and $\mathrm{Al} / \mathrm{CuO}$ mass ratio in the multilayer, which all define the total energy release, and flame temperature.

In this respect, we propose to in-situ grow gold nanoparticles (GNP) exhibiting high thermal diffusivity properties $\left(127.10^{-6} \mathrm{~m}^{2} \cdot \mathrm{s}^{-1}\right.$, i.e. well above the $\mathrm{Al}$ or $\mathrm{CuO}$ materials) inside the first $\mathrm{CuO}$ layer to produce localized hot-spots, and thus promote the redox reaction without adding an interfacial layer or manipulating the fuel and oxide layers thicknesses. $\mathrm{CuO} / \mathrm{Al}$ films with embedded GNP (CuO/Al-GNP) exhibit earlier reaction than standard ones: the ignition energy is lowered by $82 \%$ whereas the flame duration and intensity remains equal.

This study seeks to experimentally correlate observed ignition and reaction performances with local microstructure in $\mathrm{CuO} / \mathrm{Al}-\mathrm{GNP}$ multilayers using a host of characterization techniques including electronic microscopy, energy electron loss spectroscopy, thermal analysis and X-ray diffraction and identify if the GNP serves as localized heat absorbers to produce high stressed zones in the multilayer that could react under thermal stimulation. 


\section{Materials and Methods}

Material preparation. As the $\mathrm{Al} / \mathrm{CuO}$ multilayers system is well documented and characterized, it provides an ideal model-system to study the effect of mechanical properties on thermal initiation. Two $\mathrm{Al}$ rich $\mathrm{CuO} / \mathrm{Al}$ multilayers (samples) were prepared. The first one consists of 15 bilayers of $\mathrm{CuO} / \mathrm{Al}$ in which gold nanoparticles (GNP) are integrated into the first layer of $\mathrm{CuO}$. The second composite is a reference sample consisting of 15 bilayers of $\mathrm{CuO} / \mathrm{Al}$. The two samples are named thereafter $\mathrm{CuO} / \mathrm{Al}-\mathrm{GNP}$ and $\mathrm{CuO} / \mathrm{Al}$-ref, respectively. The multilayer stacks are chosen to be consistent with previous works related to integration of $\mathrm{CuO} / \mathrm{Al}$ nanolaminates in MEMS for ignition applications ${ }^{6}$ : the $\mathrm{Al} / \mathrm{CuO}$ bilayer thickness is set at $400 \mathrm{~nm}$. The $\mathrm{Al}$ to $\mathrm{CuO}$ mass ratio is therefore 2:1 (fuel-rich configuration), i.e. $\mathrm{Al}$ and $\mathrm{CuO}$ thicknesses are $200 \mathrm{~nm}$.

The multilayer stacks are magnetron-deposited following a procedure previously described. ${ }^{26,34}$ In summary, $\mathrm{Al}$ and $\mathrm{CuO}$ are sputtered from $\mathrm{Cu}$ and $\mathrm{Al}$ targets $(8$ by 3 inches sides and $1 / 4$ inches thick) using a base pressure of $5.10^{-7}$ mbar. $\mathrm{O}_{2}$ and Ar gases flow rates of 16 and 32 SCCM are used respectively for cupric oxide deposition with a partial pressure of $10^{-2}$ mbar. The Ar partial pressure during $\mathrm{Al}$ deposition is maintained at $5.10^{-3}$ mbar. The sample is cooled at ambient temperature for $600 \mathrm{~s}$ at the end of the deposition process.

Photo-deposition of Gold nanoparticles. The GNP photo-deposition process is adapted from a previously reported method. ${ }^{35}$ A $100 \mathrm{~nm}$ thick $\mathrm{CuO}$ film, sputter-deposited on a SiP wafer or glass wafer, is immersed in a mixture composed by $50 \mathrm{~mL}$ of $\mathrm{HAuCl}_{4}$ aqueous solution (precursor, $\left.\left[\mathrm{Au}^{3+}\right]=2.5 .10^{-4} \mathrm{~mol} . \mathrm{L}^{-1}\right), 0.15 \mathrm{~mL}$ of sodium citrate aqueous solution $\left([\right.$ citrate $\left.]=0.05 \mathrm{~mol} . \mathrm{L}^{-1}\right)$, $4.85 \mathrm{~mL}$ of deionized (DI) water and $5 \mathrm{~mL}$ of ethanol in order to have a final [citrate]/[ $\left.\mathrm{Au}^{3+}\right]$ ratio value of 0.6. The immersed wafer is then UV irradiated during $10 \mathrm{~min}$ at the power of $100 \mathrm{~W}$. The sample is then dried and annealed in air at $120^{\circ} \mathrm{C}$ during 10 min to ensure the anchorage of GNP 
in the $\mathrm{CuO}$ surface. After the annealing step, the samples are vigorously cleaned with DI water (around $75 \mathrm{~mL}$ for each sample) to remove all the by-products arising from the thermal decomposition of the citrate ligands. The presence of GNP is confirmed by grazed incidence Xray diffraction (GI-XRD and TEM-EDS, see supporting information Figure S1).

Characterization. The $\mathrm{CuO} / \mathrm{Al}$ multilayer films were first examined using a FEI Helios NanoLab DualBeam scanning electronic microscope (SEM). The images were obtained using a backscattered electron detector to achieve a good contrast. The elementary composition is estimated by energy dispersive X-ray analysis (EDX), with a JEOL CENTURIO-X SDD detector.

Transmission electronic microscope (TEM) cross-sectional lamellas were prepared using a focused-ion beam FIB-SEM FEI Helios NanoLab DualBeam. TEM lamellas were characterised by high-magnification TEM and scanning TEM (STEM) using a JEOL JEM-ARM200F cold-FEG instrument, operated at $200 \mathrm{kV}$. The maximum spatial resolution (in STEM mode) is $0.078 \mathrm{~nm}$. The chemical composition was analysed by energy electron loss spectroscopy (EELS), using a GIF Quantum ER imaging filter.

The phase composition of the prepared multilayers was determined using GI-XRD. This was done using a Bruker D8 Discover system with a $\mathrm{Cu} \mathrm{K} \alpha$ radiation source, $\lambda=1.5418 \AA$. The measurements were performed in $2 \theta$ mode, from $20^{\circ}$ to $80^{\circ}$, with a step of $0.02^{\circ}$. Further characterization of the multilayers is done through differential scanning calorimetry (DSC) using a NETZSCH DSC 404 F3 Pegasus device. The device is equipped with a DSC-Cp sensor type S and a Platinum furnace in a temperature range from room temperature to $1000{ }^{\circ} \mathrm{C}$. Thermal analyses were performed under constant heating rates $\left(10-40^{\circ} \mathrm{C} / \mathrm{min}\right)$ in Ar atmosphere $(99.998 \%$ pure) at a flow rate of $20 \mathrm{~mL} \cdot \mathrm{min}^{-1}$. The traces were normalized by the mass of nanothermite material (around $5 \mathrm{mg}$ ). 
By varying the heating rates, activation energies for each reaction peak were determined using the peak temperature $\left(T_{p}\right)$ fits to the Kissinger kinetic model using eq. (1).

$$
\ln \left(\frac{\beta}{T_{p}^{2}}\right)=\ln \left(\frac{A R}{E_{a}}\right)-\frac{E_{a}}{R T_{p}} \quad \text { (Eq. 1) }
$$

where $E_{a}$ is the activation energy, $\beta=d T / d t$ is the heating rate, $T_{p}$ is the peak temperature, $R$ is the gas constant and $A$ is the pre-exponential factor. By plotting $\ln \left(\beta / T_{p}{ }^{2}\right)$ versus $1 / T_{p}$ (Kissinger plot), one can easily extract $E_{a}$ by calculating the slope for each reaction peaks.

The stress magnitude is determined using a KLA-TENCOR P17 stylus profiler, by measuring the change in the substrate curvature before and after the film deposition. The residual stress $\sigma$ is inversely proportional to the change curvature radius, following the Stoney equation (eq. 2$)^{36}$ :

$$
\sigma=\frac{E_{S}}{6\left(1-v_{s}\right)} \frac{h_{S}^{2}}{h_{f}}\left(\frac{1}{R}-\frac{1}{R_{0}}\right)
$$

with $E_{s}$ the Young modulus of the substrate, $v_{s}$ the Poisson's ratio of the substrate, $h_{s}$ the substrate thickness, $h_{f}$ the film thickness, $R_{0}$ and $R$ the curvature radii of the substrate before and after the film deposition.

Ignition experiments. The sustained reactions in $\mathrm{CuO} / \mathrm{Al}$ multilayer films can be initiated via a localized hot point such as a resistive filament, resulting in self-propagating combustion fronts that propagate away from the ignition source. On-chip resistive filament (See Supporting Information Figure S2) was fabricated as follows: a $500-\mu \mathrm{m}$ thick 4-inch glass substrate is cleaned with an oxygen plasma at $800 \mathrm{~W}$ for $5 \mathrm{~min}$ to remove surface contaminations. Next, 800 -nm thick titanium and 300-nm thick gold layers are evaporated onto the surface and then patterned to define the Ti filament and Au electrical pads. 
The electrical resistance obtained is $3 \pm 0.2 \Omega$. Finally, around $12 \mathrm{~mm}^{2} \mathrm{CuO} / \mathrm{Al}$ multilayer films are patterned and sputter-deposited, as described previously in contact with the Ti filament. At the end the chip is $6.7 \times 5.6 \mathrm{~mm}$.

The Ti thin film filament is heated using a dc current of $1.8 \pm 0.1 \mathrm{~A}$ (with a compliance of $20 \mathrm{~V}$ ) corresponding to a dissipated electrical power of $10 \mathrm{~W}$. This value is reached accounting for a residual resistance value $(0.7 \pm 0.1 \Omega)$ of the electrical setup. This corresponds to a heating rate of $10^{5}-10^{6} \mathrm{~K} \cdot \mathrm{s}^{-1}$, estimated by a numerical Joule heating model, detailed in Supporting Information S3. The ignition delay of the multilayers is characterized using a photodiode (VISHAY, reference BPV10) polarized at $5 \mathrm{~V}$ placed at a few inches distance from the thermite, capable to detect and record the optical emission. The current emitted by the photodiode illuminated by the thermite reaction is measured through a dummy resistance of $1 \mathrm{k} \Omega$. All the data were processed using a homemade MATLAB code. A visual of the experimental setup is presented in Supporting Information, Figure S2.b. For each type of sample, the measurements were repeated 10 times, and the statistical values are reported.

\section{Results and discussion}

\section{Samples characterization}

High magnification TEM and SEM micrographs of CuO/Al-GNP are shown in Figure 1, revealing the GNP distribution and the internal structure of the first $\mathrm{CuO}$ layer. The images are taken in dark field, so the lightest elements appear in dark ( $\mathrm{Al})$ whereas the heaviest appear in bright $(\mathrm{Au}, \mathrm{CuO}$ ). GNP is distinguished by its high brightness (Figure 1b) inside the first $\mathrm{CuO}$ layer. The GNP size is $5-20 \mathrm{~nm}$ wide and its size dispersity is reported in Figure 1c. The size distribution was obtained by taking several SEM pictures at different magnification of the $\mathrm{CuO}$ surface. For each image, the particles were counted using ImageJ analysis software. A minority of 
bigger particles probably made of gold clusters, of a few hundreds of nanometers across are also observed. The EDS mapping (not shown) supports the presence of the different elements in each layer. The $\mathrm{Al}$ and $\mathrm{CuO}$ layers exhibit overall structures that are typical of conventional $\mathrm{CuO} / \mathrm{Al}$ films, i.e. columnar $\mathrm{CuO}$ and polycrystalline $\mathrm{Al}$ layers. However, in contrast to the reference sample, $\mathrm{CuO} / \mathrm{Al}-\mathrm{GNP}$ exhibits a few defects that develops from the bigger GNP seeds $(\sim 100 \mathrm{~nm}$ in diameter) as conical shaped defects, resulting in the formation of spherical bumps at the surface of the nanolaminate. These defects and their evolution will be described in more details in subsection Structure morphology evolution upon heating. The XRD patterns for all multilayers specimens are presented in Supporting Information $\mathrm{S} 4 . \mathrm{Al}$ and $\mathrm{CuO}$ are clearly detected whereas crystalline Au is not observed, probably due to the deep localization of the GNP within the film having a total thickness of $6 \mu \mathrm{m}$.
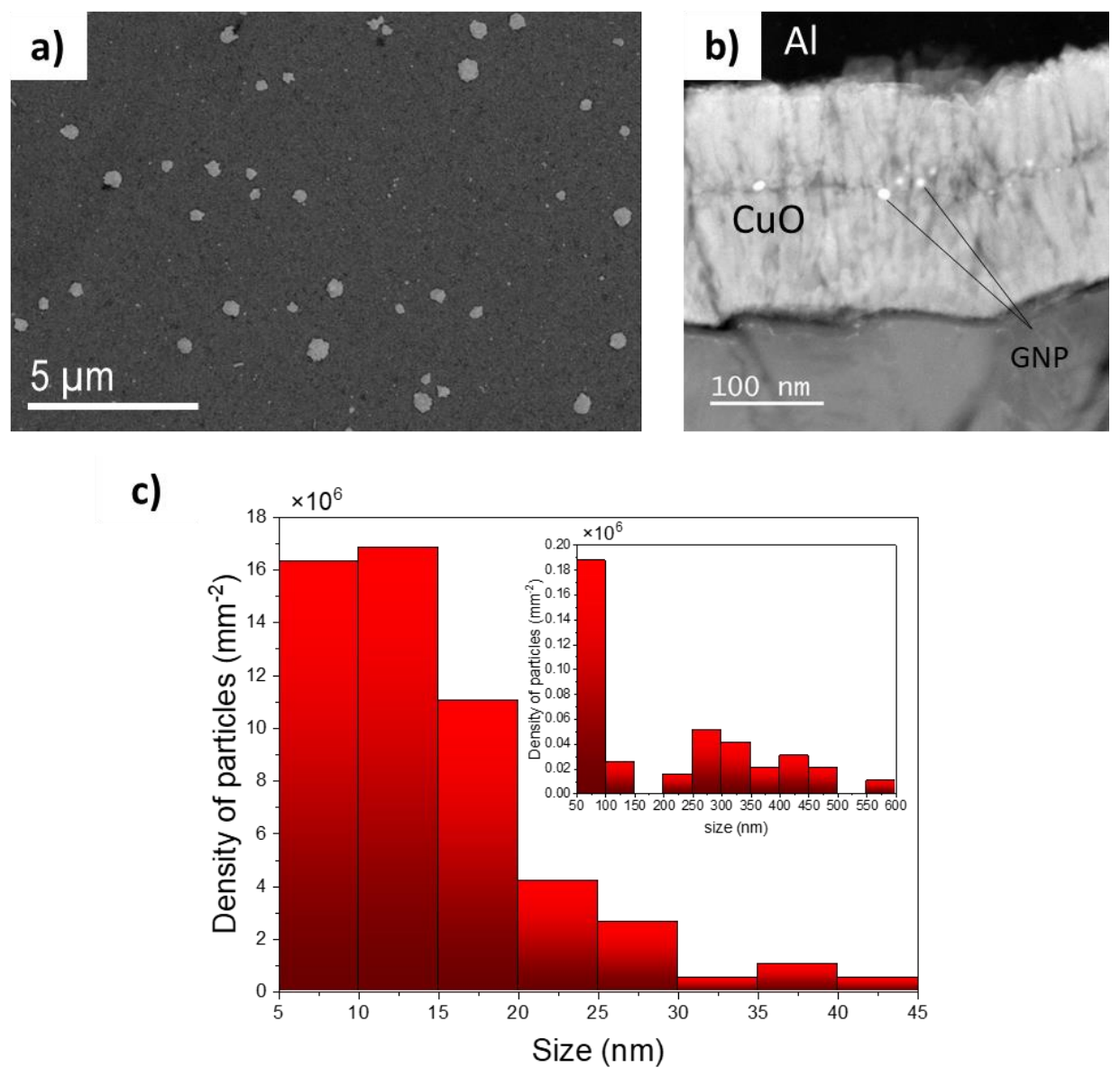
Figure 1. a) SEM image of GNP deposited on a $100 \mathrm{~nm}$-thick CUO layer; b) TEM image of the CuO/Al/GNP cross section and; c) size distribution of gold particles (GNP).

\section{Ignition experiment.}

For each sample (CuO/Al-GNP and $\mathrm{CuO} / \mathrm{Al}-\mathrm{ref})$, the measured ignition delay under $10 \mathrm{~W}$ electrical input and flame characteristics are shown in Figure 2 and summarized in Table 1.

a)

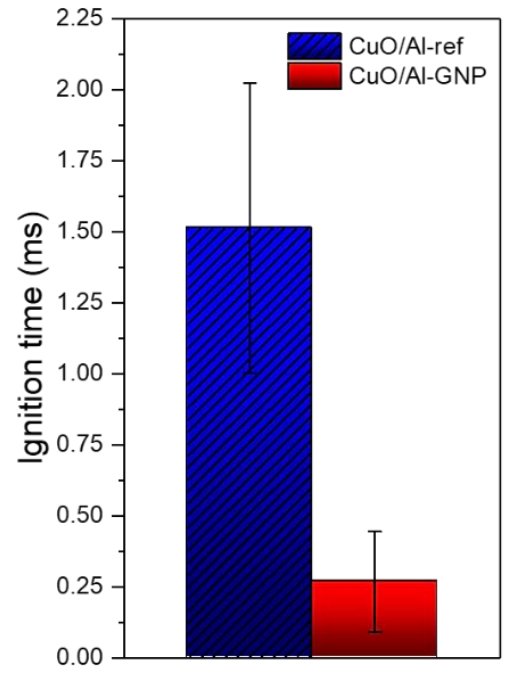

b)

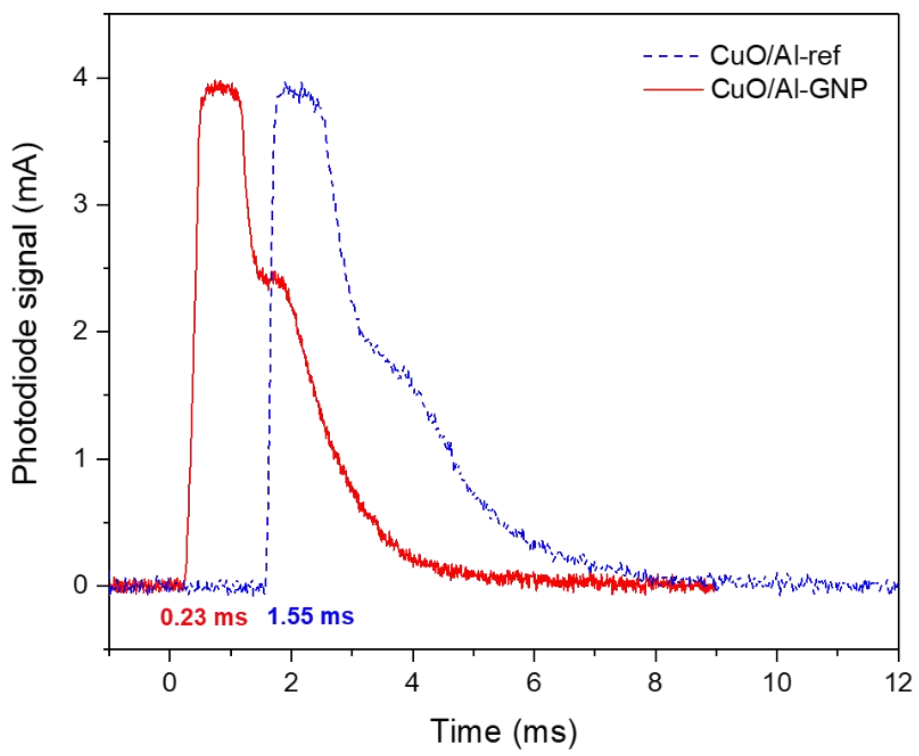

Figure 2. Result of ignition experiments for CuO/Al-ref and CuO/Al-GNP: a) ignition delay and; b) an example of photodiode signals acquired during ignition.

A clear difference in the ignition delay is observed between the two samples in Figure 2. Samples with GNP are ignited almost 6 times faster than reference ones: $0.3 \mathrm{~ms}$ for $\mathrm{CuO} / \mathrm{Al}-\mathrm{GNP}$ versus $1.5 \mathrm{~ms}$ for the reference (Figure 2a). The standard deviation of the ignition delay is about $0.2 \mathrm{~ms}$ for $\mathrm{CuO} / \mathrm{Al}-\mathrm{GNP}$ and $0.5 \mathrm{~ms}$ for the reference (see errors bars of the graph in Figure 2a). Finally, 
the analysis of the photodiode signals (one example is shown in Figure $2 \mathrm{~b}$ ) gives us some information about the energy properties, i.e. flame intensity and duration. The maximum intensity of the photocurrent and the signal width can be respectively related to the maximum temperature and the duration of the flame produced by the nanothermite combustion. The integral of the photodiode signal provides information regarding the total energy liberated during the combustion. Those characteristics are well preserved when GNP are integrated into the thermite: the flame intensity is the same (maximum photodiode current of $3.9 \mathrm{~mA}$ for both samples), whereas the signal width and integral are slightly shorter: the signal widths are $7 \pm 1$ and $8 \pm 1 \mathrm{~ms}$ and the integral of the photodiodes are 7.9 and 8.7 a.u. for $\mathrm{CuO} / \mathrm{Al}-\mathrm{GNP}$ and $\mathrm{CuO} / \mathrm{Al}$-ref, respectively (Table 1).

Table 1. Results of ignition experiments (mean value calculated on 10 ignition experiments for each sample).

\begin{tabular}{|c|c|c|c|c|}
\cline { 3 - 5 } \multicolumn{2}{c|}{} & \multicolumn{3}{c|}{ Photodiode signals characteristics } \\
\hline & $t_{\text {ignit }}(\mathrm{ms})$ & Maximum (mA) & Width (ms) & Integral (a.u.) \\
\hline CuO/Al-ref & $1.5 \pm 0.5$ & $3.95 \pm 0.10$ & $8 \pm 1$ & $8.7 \pm 0.5$ \\
\hline CuO/Al-GNP & $0.3 \pm 0.2$ & $3.89 \pm 0.04$ & $7 \pm 1$ & $7.9 \pm 0.5$ \\
\hline
\end{tabular}

\section{Thermal analysis.}

DSC analysis is routinely used to characterize energetic materials and provides details about exothermic events and total amount of energy released from materials. Figure 3 shows the DSC traces obtained for the different samples heated from the ambient to $1000{ }^{\circ} \mathrm{C}$ at a heating rate of 
$20{ }^{\circ} \mathrm{C} \cdot \mathrm{min}^{-1}$ under a controlled flow of Argon (See Supporting Information S5 for DSC repeatability).

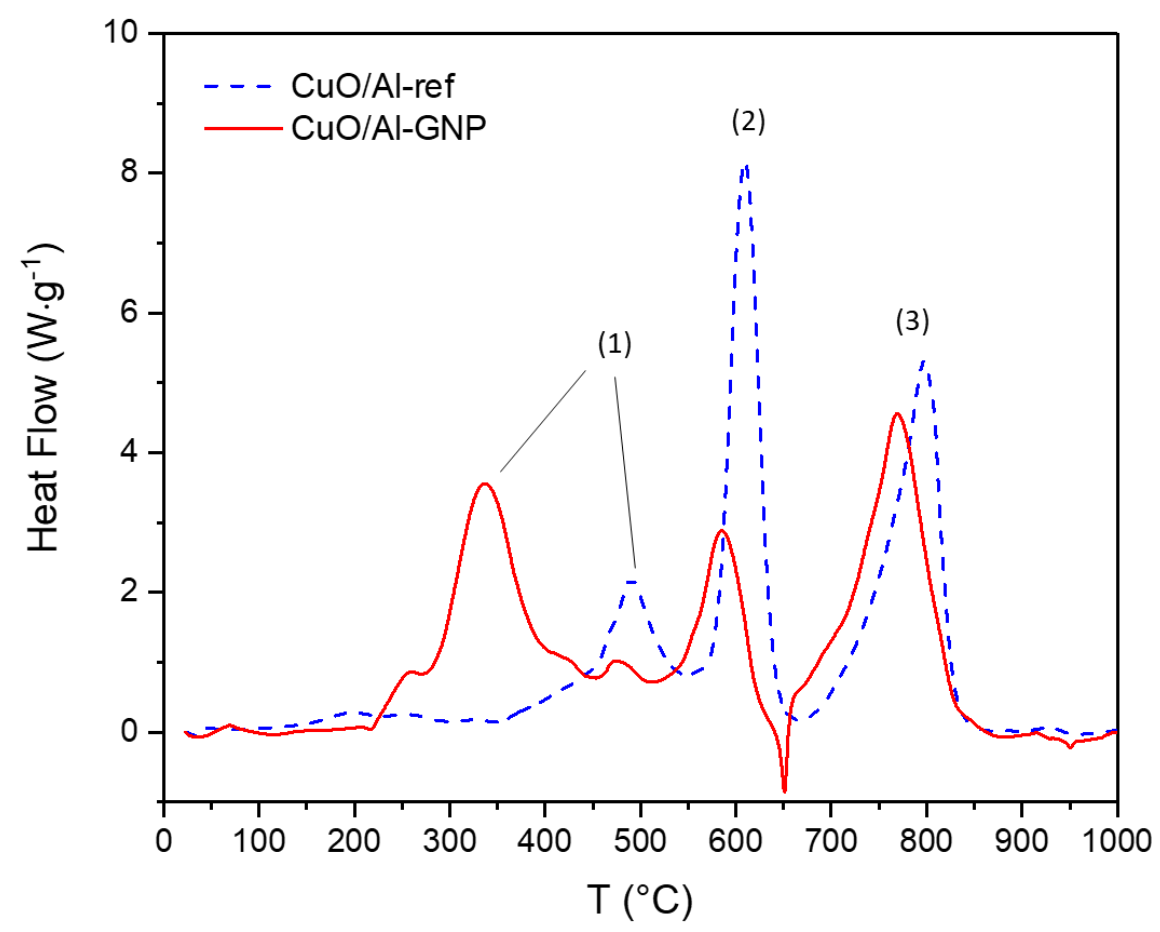

Figure 3. DSC traces of foils composed of 15 bilayers of CuO/Al-ref (blue dash curve) and $\mathrm{CuO} / \mathrm{Al}$-GNP (red solid curve), collected at $20^{\circ} \mathrm{C} \cdot \mathrm{min}^{-1}$.

The DSC trace obtained for reference multilayers (blue dash curve of Figure 3) is very similar to traces already published in the literature for fuel rich configuration. ${ }^{26} \mathrm{We}$ observe three exothermic events. A first broad exothermal (1) event is observed between 350 and $550{ }^{\circ} \mathrm{C}$ with a peak temperature at $490{ }^{\circ} \mathrm{C}$. It is followed by a strong exothermal peak at $550-650{ }^{\circ} \mathrm{C}$ with a peak temperature at $609^{\circ} \mathrm{C}$. A last exotherm at high temperature is detected between 700 and $840{ }^{\circ} \mathrm{C}$, with a peak at $797{ }^{\circ} \mathrm{C}$. Around $250-300^{\circ} \mathrm{C}$ the copper oxide releases oxygen atoms ${ }^{37,38}$ that diffuse across the natural interfacial layers to oxidize the neighbouring aluminium, thus forming amorphous alumina. Because amorphous alumina density is substantially higher than that of the naturally grown interface, its structure is mechanically degraded at $\sim 350{ }^{\circ} \mathrm{C}$ leading to the 
accelerated redox reaction. ${ }^{39}$ Then, the resulting increase in amorphous alumina layer thickness provides a barrier to the oxygen diffusion that slows down $\mathrm{Al}$ oxidation, thus reducing the heat release corresponding to the drop of the first exotherm in the DSC trace (1). The second exothermal peak (2) corresponds to the main reaction stopped by a polymorphic phase change (amorphous alumina $\rightarrow \gamma-\mathrm{Al}_{2} \mathrm{O}_{3}$ ). Then $\mathrm{Al}$ oxidation, in liquid phase, continues through the $\gamma-\mathrm{Al}_{2} \mathrm{O}_{3}$ (3), which process is activated at $700{ }^{\circ} \mathrm{C}$.

The thermal analysis of $\mathrm{CuO} / \mathrm{Al}-\mathrm{GNP}$ (red solid curve of Figure 3 ) reveals a much more complex behavior with a wider temperature profile, showing substantial differences in the two first exotherms (200-600 ${ }^{\circ} \mathrm{C}$ regime) while exhibiting similar exothermic behaviours in the higher temperature regime. Importantly, reaction onset is dramatically shifted down to $\sim 200{ }^{\circ} \mathrm{C}\left(350{ }^{\circ} \mathrm{C}\right.$ for the reference). This first exotherm peak temperature is located at $337^{\circ} \mathrm{C}$ instead of $490{ }^{\circ} \mathrm{C}$ for the reference sample and is composed of multiple elementary contributions. The second peak (2) is a bit shifted down to $586{ }^{\circ} \mathrm{C}$ and features an intensity almost 3 times lower than that of the reference. It appears that the first reaction step (oxidation of neighbouring aluminium to form amorphous alumina) is enhanced when the GNP are integrated into the first $\mathrm{CuO}$ layer. This is further discussed in sub-section Structure morphology evolution upon heating showing the evolution of the multilayer structure upon heating. Note that we also notice a bump at $\sim 475^{\circ} \mathrm{C}$, exactly centred on the first exotherm of reference sample, which could be associated to $\mathrm{Al}$ oxidation in the multilayer far from the GNP.

The heats of reaction for each peak, calculated by integrating the DSC curves over the time in the different temperature ranges, are reported in Table 2. 
Table 2. Enthalpy of reaction calculated by integrating the exothermic signal over time and normalized with respect to the film mass.

\begin{tabular}{|l|c|c|c|c|c|}
\hline & \multirow{2}{*}{$\begin{array}{c}\text { Theoretical } \\
\Delta \mathrm{H}(\mathrm{J} / \mathrm{g})^{18}\end{array}$} & \multirow{2}{*}{ Total $\Delta \mathrm{H}(\mathrm{J} / \mathrm{g})$} & \multicolumn{3}{|c|}{ Heat of reaction per peak (J.g-1) } \\
\cline { 4 - 6 } & & & Exotherm (1) & Exotherm (2) & Exotherm (3) \\
\hline CuO/Al-ref & 3300 & 2651 & 561 & 1012 & 1078 \\
\cline { 3 - 6 } & & 2986 & 1269 & 554 & 1163 \\
\hline CuO/Al-GNP & & & & & \\
\hline
\end{tabular}

The experimental $\Delta H$ of $\mathrm{CuO} / \mathrm{Al}$-ref is only $80 \%$ of the theoretical value. Thus, only $80 \%$ of the aluminium available in the layers reacts. This is mainly due to parasitic reactions, such as the formation of $\mathrm{Al}-\mathrm{Cu}$ intermetallic which occurs before $500{ }^{\circ} \mathrm{C}^{38}$ and therefore consumes a portion of the reservoir as the $\mathrm{Al}-\mathrm{Cu}$ bond formation is much less energetic than that of $\mathrm{Al}-\mathrm{O}$ bond.

Compared to $\mathrm{CuO} / \mathrm{Al}-\mathrm{ref}$, the $\mathrm{CuO} / \mathrm{Al}-\mathrm{GNP}$ multilayers feature a total experimental $\Delta H$ closer to the theoretical value (90\%), which means that the $\mathrm{Al}$ reservoir is more efficiently and quickly consumed. In $\mathrm{CuO} / \mathrm{Al}-\mathrm{GNP}$ sample, more than double mass of $\mathrm{Al}$ reacts with oxygen during the first exotherm. Consequently, the second exotherm (2) is less intense. This can be explained by two main reasons: (i) the $\mathrm{CuO} / \mathrm{Al}-\mathrm{GNP}$ features much more interfacial area due to the presence of conical nodules, (ii) also, the high-stress magnitude at the cones' boundaries lowers the diffusion barrier of $\mathrm{O}$ through interfacial layer. As a result, as soon as the $\mathrm{CuO}$ releases its oxygen $(\sim 250-$ $300{ }^{\circ} \mathrm{C}$ ), neighbouring aluminium quickly oxidizes. The amorphous alumina formed by this solidstate reaction produces a barrier that causes the end of the first peak as it is the case in $\mathrm{CuO} / \mathrm{Al}-$ 
ref. Then the oxidation is again activated (second peak (2)) when the diffusion of oxygen through amorphous alumina is thermally activated. Finally, the third reaction step, corresponding to the oxidation of melted $\mathrm{Al}$ (peak (3)) occurs and produces equivalent energy in both sample configurations, as expected since GNP only modify the first reaction step.

Next, we applied the Kissinger's method which is intensively used in interpreting DSC data for thermite materials, in order to calculate activation energies $\left(E_{a}\right)$ for each reaction step (and for each sample). The concept of reaction progress on which is based the Kissinger method, should be limited to independent reactions occurring successively after each other, within specific temperature ranges, which is not the case in our thermite system where elementary physical mechanisms interact with each other and occur concurrently at all temperatures, therefore the determination of $E_{a}$ is made with inaccuracies.

The activation energy (Figure 4) of the first exotherm (1) is highly reduced (by $61 \%$ ) by the presence of GNP, whereas the activation barriers of second and third exotherms are less affected by the GNP: $\mathrm{E}_{\mathrm{a}}$ is only lowered by $18 \%$ and $13 \%$ for the second and third exotherms, respectively. For each sample, three DSC traces were considered and very reproducible. The numerical error on the linear fit for the first peak is about $\pm 12 \mathrm{~kJ} \cdot \mathrm{mol}^{-1}$ the DSC. 
a)

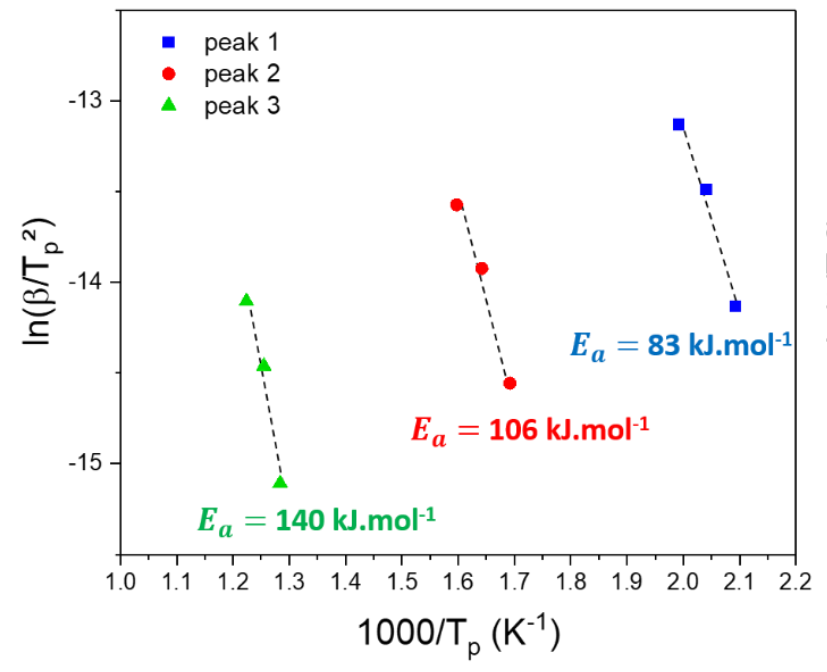

b)

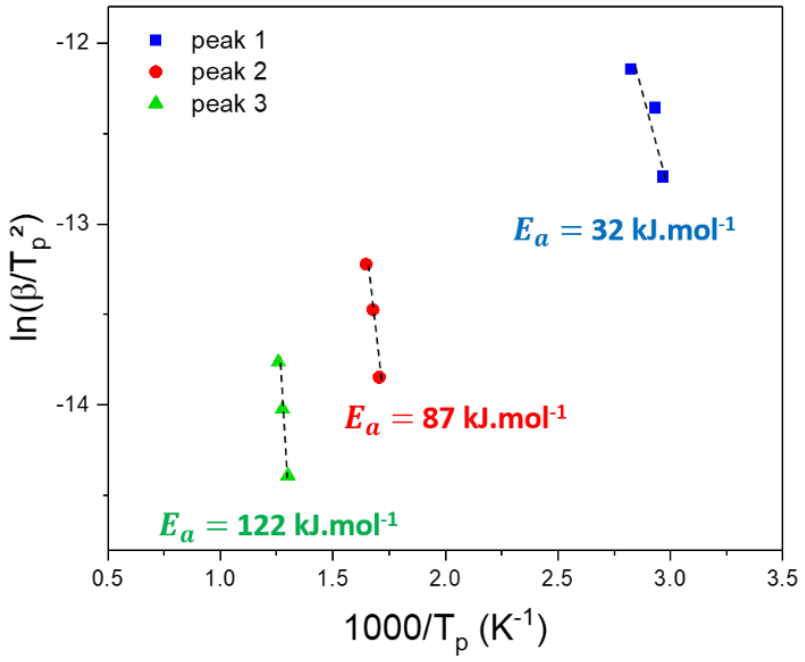

Figure 4. Kissinger plots of a) CuO/Al-ref and b) CuO/Al-GNP, giving the activation energies ( $\left.E_{a}\right)$ for the three reaction steps.

As summary, the thermal analyses showed that the $\mathrm{Al}+\mathrm{CuO}$ redox reaction starts at lower temperature, highly promoted when GNP are integrated in the first $\mathrm{CuO}$ layer. In order to understand the role of GNP in the $\mathrm{Al}+\mathrm{CuO}$ reaction mechanisms, the structural and chemical changes of the CuO/Al-GNP sample were observed by HR-TEM, EELS in STEM mode upon annealing at $400{ }^{\circ} \mathrm{C} @ 10{ }^{\circ} \mathrm{C} / \mathrm{min}$.

\section{Structure morphology evolution upon heating.}

Figure 5 shows cross-sectional images of $\mathrm{CuO} / \mathrm{Al}$-GNP samples, as deposited (Figure 5a) and after ex situ annealing at $400{ }^{\circ} \mathrm{C}$ in argon atmosphere (Figure 5b). HR-TEM micrographs of reference (Figure 5c,d) and CuO/Al-GNP (Figure 5e,f) are also presented, with zooms on the microstructure. The large bright spot located in the first $\mathrm{CuO}$ layer (Figure 5a) is a zoom on one gold particle being $\sim 100-200 \mathrm{~nm}$ in size. We clearly see that, the presence of the GNP alters the layers shape, and forms "nodular defects". The nodules form parabolic shapes, from the gold seeds 
of diameter $d$ to the dome surface of diameter $D$ (Figure 6), following the relation: $D^{2} \sim T \times d$, with $T$ the $\mathrm{Al} / \mathrm{CuO}$ multilayered film thickness.
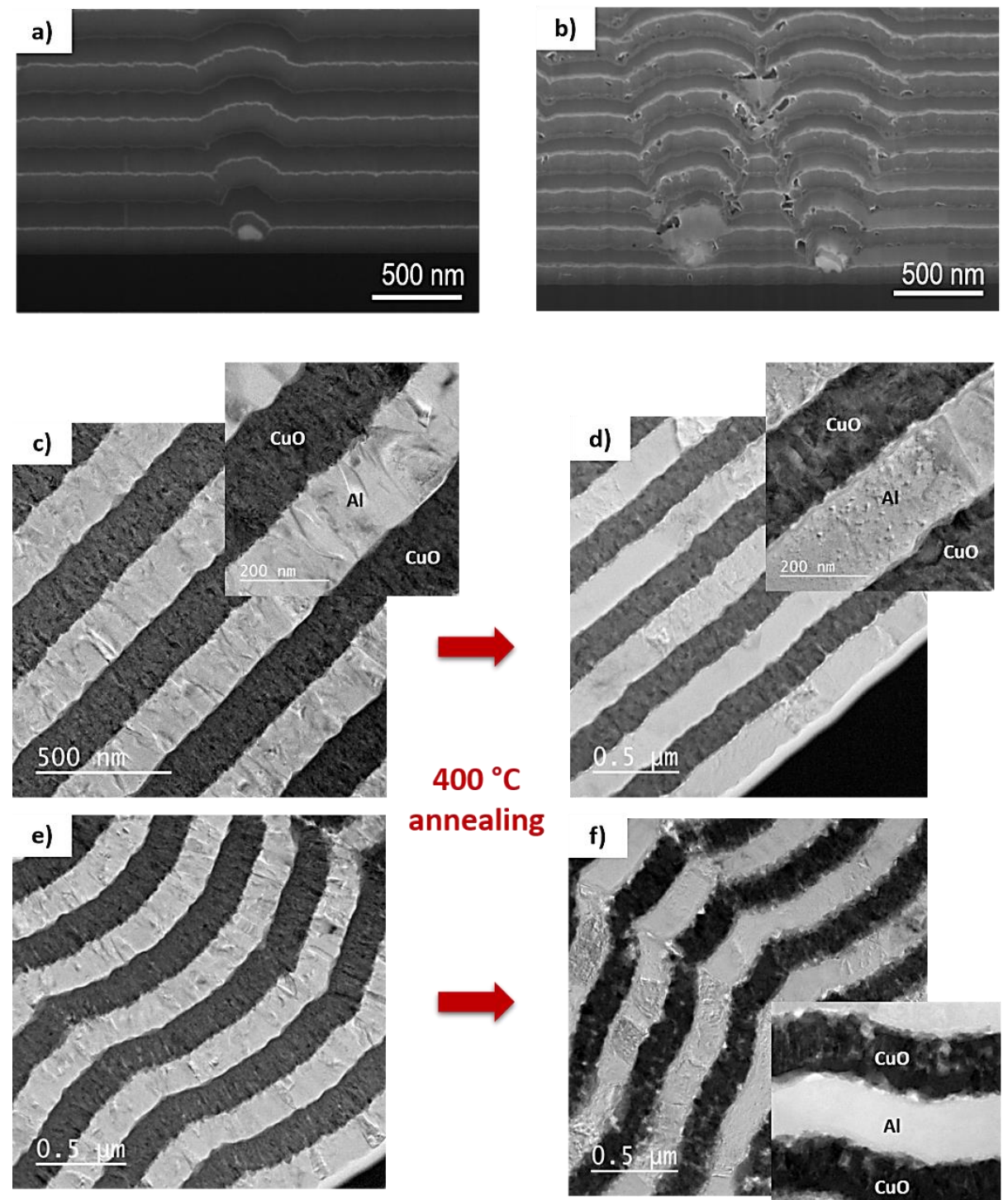

annealing

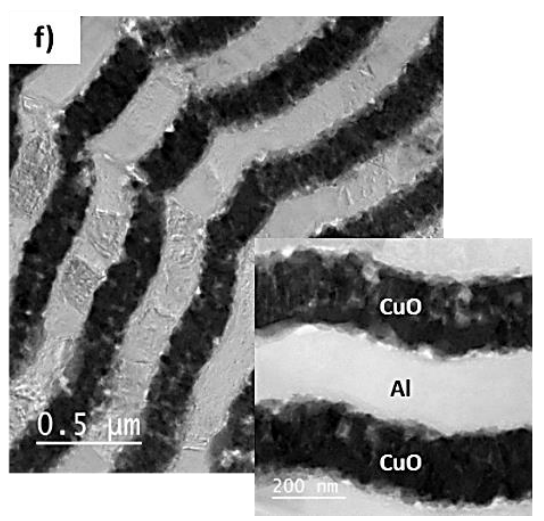

Figure 5. Cross-sectional images of a) one as-deposited CuO/Al-GNP and b) $400{ }^{\circ} \mathrm{C}$ annealed CuO/Al-GNP. HR-TEM micrographs of c) as-deposited CuO/Al-ref; d) $400{ }^{\circ} \mathrm{C}$ annealed CuO/Alref; e) as-deposited CuO/Al-GNP and f) $400{ }^{\circ} \mathrm{C}$ annealed CuO/Al-GNP. 
a)

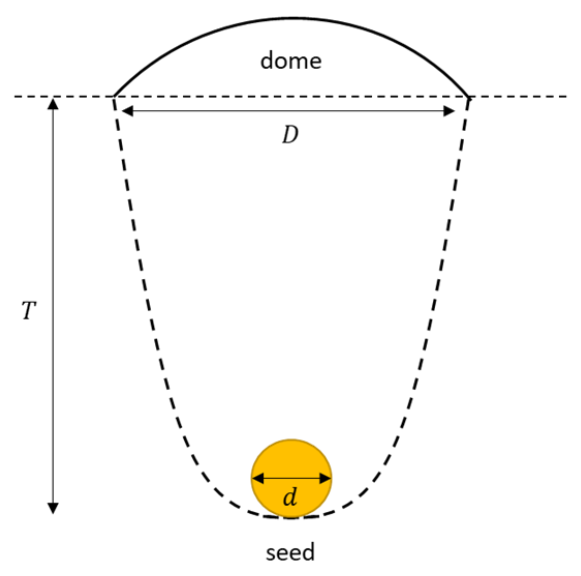

b)

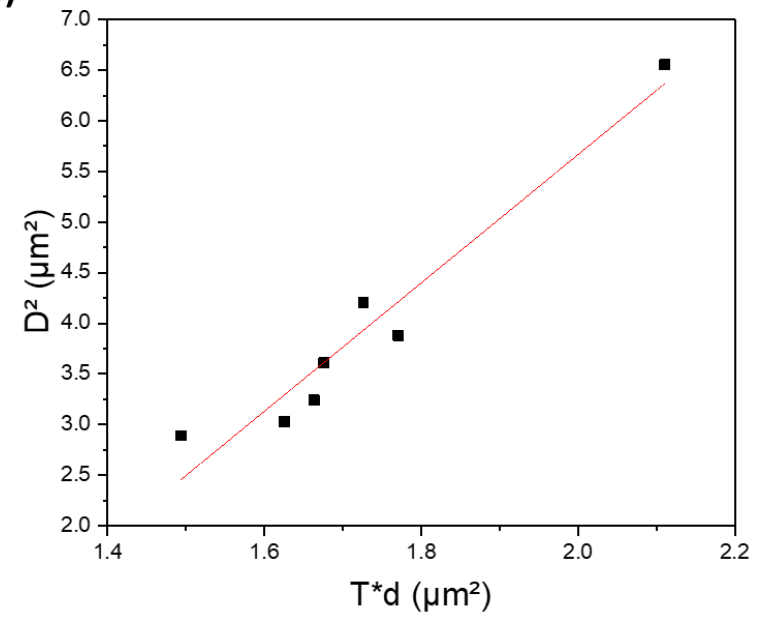

Figure 6. Geometrical characterization of nodular defects presenting a) a schematic of a nodule induced by a particle (seed) with a diameter $d$ and $b$ ) experimental relation between $d$ and $D$ parameters.

The film stress magnitude with and without GNP evaluated by ex situ wafer-curvature measurements after multilayer growth is $240 \mathrm{MPa}$ and $319 \mathrm{MPa}$ for $\mathrm{CuO} / \mathrm{Al}-\mathrm{GNP}$ and $\mathrm{CuO} / \mathrm{Al}-$ ref, respectively, clearly pointing that the GNPs integrated into the first $\mathrm{CuO}$ layer do not weaken the film, but rather relax the stress through local deformation (nodular defects).

After ramping up to $400{ }^{\circ} \mathrm{C}$, we observe an important structural damage (Figure 5b) and morphological changes. The damage is also observed in TEM (Figure 5f). Numerous cracks, holes and voids appear as well as alumina portions. While most of these defects are clearly decorating the nodule boundaries, some are also dispersed in the multilayers, at the reactant interfaces. As a consequence, the reactant interfaces are now ill-defined with thicknesses varying from 20 to 50 $\mathrm{nm}$, which represents about 10 to $25 \%$ of the Al layer. Furthermore, the initial columnar structure of the $\mathrm{CuO}$ grains is partially lost after the annealing step, which testifies the densification of oxide 
layers after its reduction (see EELS section). To summarize, we believe that damage of the multilayer locally favors the contact between the $\mathrm{Al}$ and $\mathrm{CuO}$ reservoirs through highly defective interfaces, which in turn will favor the diffusion of oxygen atoms from $\mathrm{CuO}$ to $\mathrm{Al}$ layers. Note that these damages, or extended defects, are also consistent with the enhancement of the first DSC peak

as compared to the reference (Figure 3). Interestingly, Dong et al. ${ }^{40}$ showed that mechanical stress affects the diffusivity of oxygen atoms by reducing the activation energy barrier for their migration through the interfacial layer, leading to an enhancement of the oxidation rate (the alumina growth being diffusion limited, as the oxidation reaction of aluminium is spontaneous).

For comparison, $\mathrm{CuO} / \mathrm{Al}-\mathrm{ref}$ has been observed after being annealed in the same conditions (Figure 5c and Figure 5d). Without GNP, the multilayers structure remains intact and we observe a substantial thickening of the interfacial alumina from $4 \mathrm{~nm}$ to about $15 \mathrm{~nm}$ without formation of extended defective domains as observed with GNP, which is in good agreement with the previous observations. $^{38}$

\section{Chemical evolution upon heating.}

Additionally, crystalline phases are examined by GI-XRD. Typically, in the deposited films, only $\mathrm{Al}$ and $\mathrm{CuO}$ phases are detected. After annealing at $400{ }^{\circ} \mathrm{C}$, the $\mathrm{CuO}$ is partially reduced into $\mathrm{Cu}_{2} \mathrm{O}$. The XRD spectra (Supporting Information S6) show a clear increase and well-defined $\mathrm{Cu}_{2} \mathrm{O}$ peaks with a small detection of a broad $\mathrm{Cu}$ peak for the $\mathrm{CuO} / \mathrm{Al}$-GNP sample. A crystalline $\mathrm{Al}_{2} \mathrm{O}_{3}$ phase is not yet detected, as it is still in its amorphous phase.

Electron Energy Loss Spectroscopy carried out in scanning mode was used to correlate elemental distribution of atoms (namely $\mathrm{Cu}$ and $\mathrm{Al}$ atoms) with structural aspects derived from both TEM images and XRD spectra (CuO, $\mathrm{Al}$, interfaces and their phases changes), after annealing at 400 
${ }^{\circ} \mathrm{C}$. The Figure $7 \mathrm{a}$ and Figure $7 \mathrm{~b}$ show high magnification TEM images and EELS diagrams taken in two different high-stressed zones around one nodule's boundary (represented in black dash line). Following the contrast, the oxide layer appears in bright while Al is dark. The Energy Loss Near Edge Structure (ELNES) is acquired along lines scan of $130.5 \mathrm{~nm}$ and $285.6 \mathrm{~nm}$, with a step of 14.5 and $23.8 \mathrm{~nm}$ respectively (indicated by the colour bar on the micrographs). The first diagram (Figure 7a) is acquired along the non-well defined interface between oxide and Al layers, while the second one (Figure 7b) is taken inside a failure at the nodule boundary. The Cu-L-edge ELNES is characterized by two main peaks corresponding to the transitions of $2 \mathrm{p}_{1 / 2}\left(\mathrm{~L}_{2}\right)$ and $2 \mathrm{p}_{3 / 2}\left(\mathrm{~L}_{3}\right)$ electrons toward 3d orbitals, around 933 and $955 \mathrm{eV}$ respectively. The $\mathrm{L}_{2}$ peak intensity represents roughly the half of the $\mathrm{L}_{3}$ intensity, which is consistent with previous work. ${ }^{41,42}$ The O-K-edge ELNES, is characterized by a weak peak at around $532 \mathrm{eV}$. Note that the background intensity of spectra is always subtracted using a power law fit. The complete EELS diagrams can be found in Supporting Information S6.

By getting closer to the Al layer (from black to red in the line scan of Figure 7a the $\mathrm{Cu}-\mathrm{L}_{3}$ peaks are shifted to higher energies $(932.7 \mathrm{eV}$ to $935.1 \mathrm{eV})$, which corresponds to the reduction from $\mathrm{Cu}^{2+}$ to $\mathrm{Cu}^{+}\left(4 \mathrm{CuO} \rightarrow 2 \mathrm{Cu}_{2} \mathrm{O}+\mathrm{O}_{2}\right)$. A similar shift appears for $\mathrm{L}_{2}$ edge. Moreover, we can notice that the first three $\mathrm{L}_{3}$ peaks (in black) are not sharp peaks and exhibit a second maximum, which matches with $\mathrm{Cu}^{+}$peaks at $935.1 \mathrm{eV}$ (in orange). Thus, the bright layer would not be just $\mathrm{CuO}$, but composed by co-existing $\mathrm{CuO}$ and $\mathrm{Cu}_{2} \mathrm{O}$ phases. It is also possible that other metastable phases, such as $\mathrm{Cu}_{4} \mathrm{O}_{3}$ coexist too, which is difficult to assess from our data. This shows that, at $400{ }^{\circ} \mathrm{C}$ the reduction process is already in an advanced stage, in particular around critical zones where mechanical fractures are developed, which is in good agreement with the previous DSC analysis (Figure 3). 
Concerning the Figure $7 \mathrm{~b}$, the line scan peak at $532 \mathrm{eV}$ in the $\mathrm{O}-\mathrm{K}$ edge ELNES indicates the presence of portions of alumina following the nodule boundary and positioned within the Al layer. Such a defect and its location are never observed in conventional $\mathrm{Al} / \mathrm{CuO}$ stacks, where alumina is always located at the $\mathrm{Al} / \mathrm{CuO}$ interface ${ }^{38}$ Interestingly, we notice a pre-peak around $524 \mathrm{eV}$ which is consistent with the presence of gaseous oxygen (similar to oxygen molecules signature), liberated during the reduction of $\mathrm{CuO}\left(4 \mathrm{CuO} \rightarrow 2 \mathrm{Cu}_{2} \mathrm{O}+\mathrm{O}_{2}\right)$, which has already been observed in previous works. ${ }^{43}$ The presence of gaseous oxygen and defects could possibly enhance the degradation and mechanical failure of the multilayers along the boundary, by facilitating oxygen migration pathways towards $\mathrm{Al}$ layers whereas in conventional $\mathrm{Al} / \mathrm{CuO}$ multilayers, the $\mathrm{O}$ release and subsequent alumina growth occurs only at the interface. ${ }^{38}$ 


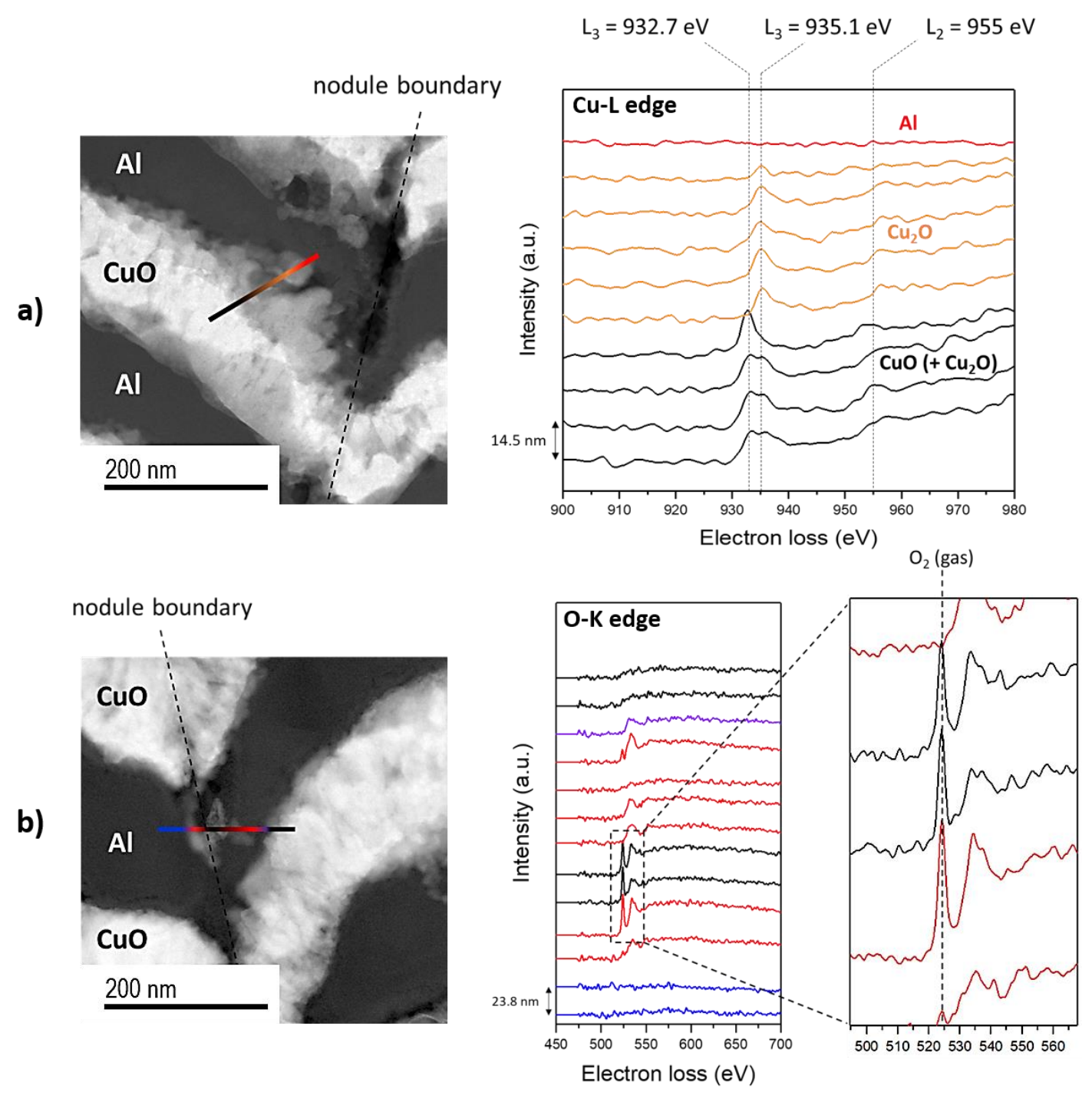

Figure 7. EELS spectra of a) $\mathrm{Cu}$-L edge and b) $\mathrm{O}$-K edge acquired within CuO/Al-GNP sample, along a line scan (black dashed line) displayed on the corresponding TEM micrograph on the left. The background intensity of spectra is always subtracted using a power law fit.

Reaction leading to ignition.

The mechanisms described in previous sections make it possible to interpret the ignition results and DSC analysis obtained for $\mathrm{CuO} / \mathrm{Al}-\mathrm{GNP}$ samples in comparison with $\mathrm{CuO} / \mathrm{Al}$-ref. Integrating GNP inside the reactive film induces nodular defects around nanoparticles, especially around the largest gold aggregates whose size is in the order of one hundred of nanometers, alters the shape 
of layers along parabolic boundaries. At room temperature, the $\mathrm{CuO} / \mathrm{Al}-\mathrm{GNP}$ films are thermally stable and do not exhibit any increase of the mechanical stress compared to the reference. However, under thermal stimulation, the $\mathrm{Al}+\mathrm{CuO}$ reaction quickly initiates, preferentially in the nodular defects, and at the seeding location surrounding nanoparticles.

As gold features a high thermal diffusivity $\left(127.10^{-6} \mathrm{~m}^{2} \cdot \mathrm{s}^{-1}\right)$, much higher than $\mathrm{CuO}\left(9.10^{-6} \mathrm{~m}^{2} \cdot \mathrm{s}^{-}\right.$ ${ }^{1}$ ), we suggest that the GNP absorbs heat, and, locally and quickly reaches high temperature thus producing high thermal stress. The stress propagates along the conical boundaries induced by GNPs, as observed by TEM images, unravelling chemical reactions and defect extension along these boundaries and across the layers. Then, when the local stress magnitude reaches a critical value, difficult to estimate or measure, the multilayer film disintegrates and pieces of unreacted $\mathrm{Al}$ are ejected and burn in condensed as gas phase in the surrounding environment as supported by the analysis of the reaction debris.

Microscopy images of reaction debris (Figure 8) that have been collected after the reaction show that both $\mathrm{CuO} / \mathrm{Al}$-ref and $\mathrm{CuO} / \mathrm{Al}-\mathrm{GNP}$ produce two types of residues: micron-sized spherical particles of alumina (2-5 $\mu \mathrm{m}$ in diameter) mixed with some larger (10-50 $\mu \mathrm{m}$ in size, not shown in the images) random shaped aggregates made of two components: alumina and copper (See Supporting Information Figure S8 for chemical mapping). Importantly, CuO/Al-GNP samples produce much more debris than $\mathrm{CuO} / \mathrm{Al}-\mathrm{ref}$ ones: 1289 residues / $\mathrm{mm}^{2}$ for $\mathrm{CuO} / \mathrm{Al}-\mathrm{GNP}$ samples versus 227 residues $/ \mathrm{mm}^{2}$ for $\mathrm{CuO} / \mathrm{Al}-$ ref. Debris analysis clearly supports that most of the reactional process proceeds in the condensed and gas phase in the air. 

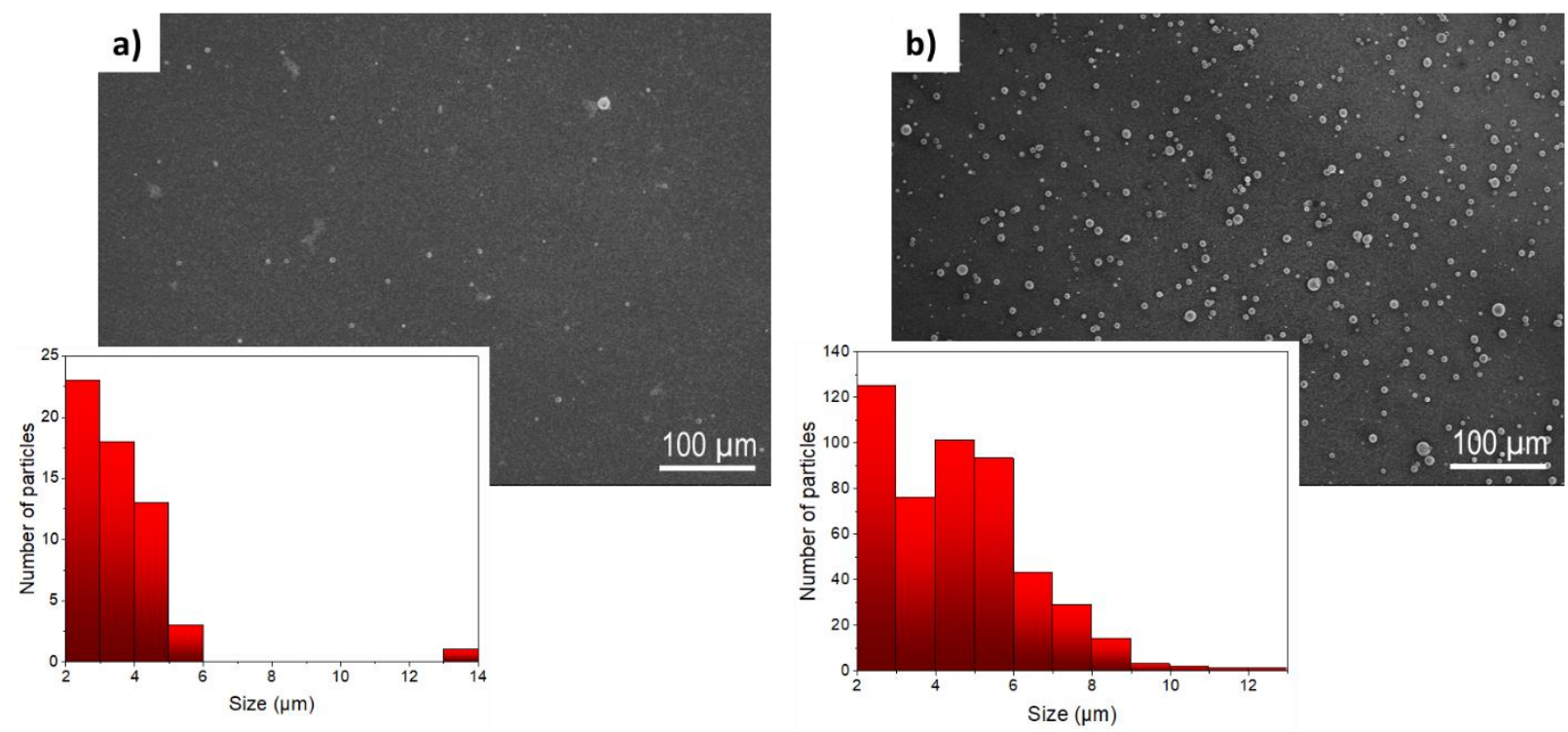

Figure 8. SEM images of reaction residues from the $\mathrm{Al}+\mathrm{CuO}$ reaction, for a) $\mathrm{CuO} / \mathrm{Al}$-ref and $b$ ) CuO/Al-GNP collected on Si wafers during the ignition experiments. Inset histograms show the sizes distribution of residues.

\section{Conclusion}

In this work, we have proposed an innovative nano-engineering solution to reduce the energy barriers and consequently the ignition temperature of $\mathrm{CuO} / \mathrm{Al}$ reactive multilayers without manipulating the fuel and oxide layer thickness. Gold nanoparticles (5- $25 \mathrm{~nm}$ in size with some being $100 \mathrm{~nm}$ in size) are uniformly grown inside the first $\mathrm{CuO}$ layer. At room temperature, the $\mathrm{CuO} / \mathrm{Al}$ films with gold nanoparticles inside are mechanically and thermally stable. But, under thermal stimulation, the $\mathrm{Al}+\mathrm{CuO}$ reaction triggers at low temperature, $250{ }^{\circ} \mathrm{C}$ against $400{ }^{\circ} \mathrm{C}$ for same thermite films without nanoparticles. This leads to faster ignition delays, being roughly one third of those obtained for reference thermite films without nanoparticles. From microscopic observations, we deduced that gold nanoparticles embedded into the $\mathrm{CuO}$ matrix serve as localized heat absorbers. Under thermal stimulation, they produce localized hot-spots and thus induce 
highly-stressed zones that trigger the $\mathrm{Al}+\mathrm{CuO}$ reaction at $250{ }^{\circ} \mathrm{C}$ whereas standard $\mathrm{CuO} / \mathrm{Al}$ films initiate at $400{ }^{\circ} \mathrm{C}$. We also experimentally showed that the $\mathrm{CuO} / \mathrm{Al}$ films with embedded gold nanoparticles exhibit more efficient reaction compared to standard ones: the heat of reaction reaches $90 \%$ of the theoretical value against $\sim 80 \%$ for standard multilayered films. Finally, the analysis of reaction products showed that the multilayer early breaks projecting unreacted Al droplets that burn into the environment. We consider that these results open new perspectives in the field of interface engineering. While the leading trend was focused on the chemical modification of barrier layers or thicknesses/reactant ratio, we here propose a more versatile and efficient way to tune the thermite reaction by controlling its internal stress.

\section{Associated content}

\section{Supporting Information}

Details on the ignition device and experimental setup for ignition tests; the thermal model used to predict ignition temperature; XRD and TEM-EELS characterizations of the $\mathrm{Al} / \mathrm{CuO}-\mathrm{GNP}$ as deposited and after annealing at $400{ }^{\circ} \mathrm{C}$; SEM-EDS images of reaction debris; DSC curves of Al/CuO-GNP foils. This material is available free of charge via the Internet at http://pubs.acs.org.

\section{Author information}

\section{Corresponding author}

Correspondence to: Carole Rossi, carole.rossi@laas.fr

\section{Author contributions}

B. J. prepared the samples and performed all the characterization measurements. J. C. performed the gold nanoparticles deposition and stabilization. C. J. prepared the lamellas and performed the microscopic observations. A. E. provided support the manuscript preparation. C. R. 
provided support for the manuscript preparation and supervised the research. The manuscript was written through contributions of all authors. All authors have given approval to the final version of the manuscript.

\section{Competing financial interests}

The authors declare no competing financial interests.

\section{Funding Sources}

C.R. received funding from the European Research Council (ERC) under the European Union's Horizon 2020 research and innovation programme (grant agreement No 832889 - PyroSafe). L.S. received funding for sputter deposition equipment from FEDER/Region Occitanie program Grant THERMIE.

\section{Acknowledgment}

The

authors

acknowledge

support

from

the European Research Council (H2020 Excellent Science) Researcher Award (grant 832889 PyroSafe) and the Occitanie Region / European Union for their FEDER support (THERMIE grant). The authors thank Séverine Vivies from LAAS-CNRS and Teresa Hungria-Hernandez from "Centre de Micro Caractérisation Raymond Castaing (UMS 3623)" for their great support with samples preparation and TEM experiments.

\section{References}

(1) Prakash, A.; McCormick, A. V.; Zachariah, M. R. Tuning the Reactivity of Energetic Nanoparticles by Creation of a Core-Shell Nanostructure. Nano Lett. 2005, 5 (7), 13571360. https://doi.org/10.1021/n10506251.

(2) Dreizin, E. L. Metal-Based Reactive Nanomaterials. Progress in Energy and Combustion Science 2009, 35 (2), 141-167. https://doi.org/10.1016/j.pecs.2008.09.001. 
(3) Liu, Y.; Gao, B.; Qiao, Z.; Hu, Y.; Zheng, W.; Zhang, L.; Zhou, Y.; Ji, G.; Yang, G. GramScale Synthesis of Graphene Quantum Dots from Single Carbon Atoms Growth via Energetic Material Deflagration. Chem. Mater. 2015, 27 (12), 4319-4327. https://doi.org/10.1021/acs.chemmater.5b00774.

(4) Zhou, X.; Torabi, M.; Lu, J.; Shen, R.; Zhang, K. Nanostructured Energetic Composites: Synthesis, Ignition/Combustion Modeling, and Applications. ACS Appl. Mater. Interfaces 2014, 6 (5), 3058-3074. https://doi.org/10.1021/am4058138.

(5) Wang, A.; Bok, S.; Thiruvengadathan, R.; Gangopadhyay, K.; McFarland, J. A.; Maschmann, M. R.; Gangopadhyay, S. Reactive Nanoenergetic Graphene Aerogel Synthesized by One-Step Chemical Reduction. Combustion and Flame 2018, 196, 400-406. https://doi.org/10.1016/j.combustflame.2018.06.034.

(6) Nicollet, A.; Lahiner, G.; Belisario, A.; Souleille, S.; Djafari-Rouhani, M.; Estève, A.; Rossi, C. Investigation of $\mathrm{Al} / \mathrm{CuO}$ Multilayered Thermite Ignition. Journal of Applied Physics 2017, 121 (3), 034503. https://doi.org/10.1063/1.4974288.

(7) Taton, G.; Lagrange, D.; Conedera, V.; Renaud, L.; Rossi, C. Micro-Chip Initiator Realized by Integrating $\mathrm{Al} / \mathrm{CuO}$ Multilayer Nanothermite on Polymeric Membrane. J. Micromech. Microeng. 2013, 23 (10), 105009. https://doi.org/10.1088/0960-1317/23/10/105009.

(8) Guo, W.; Chang, S.; Cao, J.; Wu, L.; Shen, R.; Ye, Y. Precisely Controlled Reactive Multilayer Films with Excellent Energy Release Property for Laser-Induced Ignition. Nanoscale Res Lett 2019, 14 (1), 301. https://doi.org/10.1186/s11671-019-3124-6.

(9) Zhang, D.; Pei, R.; Peng, X.; Xiang, Q.; Wang, X. Environment-Friendly Formation of High Energetic Nano-Al/Fe2O3 Bilayer by Aqueous Electrophoretic Deposition. Propellants, Explosives, Pyrotechnics n/a (n/a). https://doi.org/10.1002/prep.201900025.

(10) Xu, J.; Tai, Y.; Shen, Y.; Dai, J.; Xu, W.; Ye, Y.; Shen, R.; Hu, Y. Characteristics of Energetic Semiconductor Bridge Initiator Based on Different Stoichiometric Ratios of Al/MoO3 Reactive Multilayer Films under Capacitor Discharge Conditions. Sensors and Actuators A: Physical 2019, 296, 241-248. https://doi.org/10.1016/j.sna.2019.07.015.

(11) Martirosyan, K. S.; Wang, L.; Vicent, A.; Luss, D. Nanoenergetic Gas-Generators: Design and Performance. Prop., Explos., Pyrotech. 2009, NA-NA. https://doi.org/10.1002/prep.200800059.

(12) Wu, T.; Wang, X.; Zavalij, P. Y.; DeLisio, J. B.; Wang, H.; Zachariah, M. R. Performance of Iodine Oxides/Iodic Acids as Oxidizers in Thermite Systems. Combustion and Flame 2018, 191, 335-342. https://doi.org/10.1016/j.combustflame.2018.01.017.

(13) Jacob, R. J.; Hill, K. J.; Yang, Y.; Pantoya, M. L.; Zachariah, M. R. Pre-Stressing Aluminum Nanoparticles as a Strategy to Enhance Reactivity of Nanothermite Composites. Combustion and Flame 2019, 205, 33-40. https://doi.org/10.1016/j.combustflame.2019.03.024.

(14) Wang, H.; Rehwoldt, M.; Kline, D. J.; Wu, T.; Wang, P.; Zachariah, M. R. Comparison Study of the Ignition and Combustion Characteristics of Directly-Written Al/PVDF, Al/Viton and Al/THV Composites. Combustion and Flame 2019, 201, 181-186. https://doi.org/10.1016/j.combustflame.2018.12.031.

(15) Hastings, D. L.; Schoenitz, M.; Dreizin, E. L. High Density Reactive Composite Powders. Journal of Alloys and Compounds 2018, 735, 1863-1870. https://doi.org/10.1016/j.jallcom.2017.11.345. 
(16) Qin, L.; Gong, T.; Hao, H.; Wang, K.; Feng, H. Core-Shell-Structured Nanothermites Synthesized by Atomic Layer Deposition. J Nanopart Res 2013, 15 (12), 2150. https://doi.org/10.1007/s11051-013-2150-z.

(17) Levitas, V. I.; McCollum, J.; Pantoya, M. Pre-Stressing Micron-Scale Aluminum CoreShell Particles to Improve Reactivity. Scientific Reports 2015, 5, 7879. https://doi.org/10.1038/srep07879.

(18) Petrantoni, M.; Rossi, C.; Salvagnac, L.; Conédéra, V.; Estève, A.; Tenailleau, C.; Alphonse, P.; Chabal, Y. J. Multilayered $\mathrm{Al} / \mathrm{CuO}$ Thermite Formation by Reactive Magnetron Sputtering: Nano versus Micro. Journal of Applied Physics 2010, 108.

(19) Adams, D. P. Reactive Multilayers Fabricated by Vapor Deposition: A Critical Review. Thin Solid Films 2015, 576, 98-128. https://doi.org/10.1016/j.tsf.2014.09.042.

(20) Yarrington, C. D.; Abere, M. J.; Adams, D. P.; Hobbs, M. L. Reactive Nanolaminate PulsedLaser Ignition Mechanism: Modeling and Experimental Evidence of Diffusion Limited Reactions. Journal of Applied Physics 2017, 121 (13), 134301. https://doi.org/10.1063/1.4979578.

(21) Blobaum, K. J.; Wagner, A. J.; Plitzko, J. M.; Van Heerden, D.; Fairbrother, D. H.; Weihs, T. P. Investigating the Reaction Path and Growth Kinetics in $\mathrm{CuOx} / \mathrm{Al}$ Multilayer Foils. Journal of Applied Physics 2003, 94 (5), 2923-2929. https://doi.org/10.1063/1.1598297.

(22) Xu, J.; Shen, Y.; Wang, C.; Dai, J.; Tai, Y.; Ye, Y.; Shen, R.; Wang, H.; Zachariah, M. R. Controlling the Energetic Characteristics of Micro Energy Storage Device by in Situ Deposition $\mathrm{Al} / \mathrm{MoO} 3$ Nanolaminates with Varying Internal Structure. Chemical Engineering Journal 2019, 373, 345-354. https://doi.org/10.1016/j.cej.2019.04.205.

(23) Zhu, P.; Shen, R.; Ye, Y.; Fu, S.; Li, D. Characterization of $\mathrm{Al} / \mathrm{CuO}$ Nanoenergetic Multilayer Films Integrated with Semiconductor Bridge for Initiator Applications. Journal of Applied Physics 2013, 113 (18), 184505. https://doi.org/10.1063/1.4804315.

(24) Glavier, L.; Nicollet, A.; Jouot, F.; Martin, B.; Barberon, J.; Renaud, L.; Rossi, C. Nanothermite/RDX-Based Miniature Device for Impact Ignition of High Explosives. Propellants, Explosives, Pyrotechnics 2017, $42 \quad$ (3), 308-317. https://doi.org/10.1002/prep.201600154.

(25) Kinsey, A. H.; Slusarski, K.; Woll, K.; Gibbins, D.; Weihs, T. P. Effect of Dilution on Reaction Properties and Bonds Formed Using Mechanically Processed Dilute Thermite Foils. J Mater Sci 2016, 51 (12), 5738-5749. https://doi.org/10.1007/s10853-016-9876-9.

(26) Rossi, C. Engineering of $\mathrm{Al} / \mathrm{CuO}$ Reactive Multilayer Thin Films for Tunable Initiation and Actuation. Prop., Explos., Pyrotech. 2019, $44 \quad$ (1), 94-108. https://doi.org/10.1002/prep.201800045.

(27) Manesh, N. A.; Basu, S.; Kumar, R. Experimental Flame Speed in Multi-Layered NanoEnergetic Materials. Combustion and Flame 2010, 157 (3), 476-480. https://doi.org/10.1016/j.combustflame.2009.07.011.

(28) Lahiner, G.; Nicollet, A.; Zapata, J.; Marín, L.; Richard, N.; Rouhani, M. D.; Rossi, C.; Estève, A. A Diffusion-Reaction Scheme for Modeling Ignition and Self-Propagating Reactions in $\mathrm{Al} / \mathrm{CuO}$ Multilayered Thin Films. Journal of Applied Physics 2017, 122 (15), 155105. https://doi.org/10.1063/1.5000312.

(29) Bahrami, M.; Taton, G.; Conédéra, V.; Salvagnac, L.; Tenailleau, C.; Alphonse, P.; Rossi, C. Magnetron Sputtered Al-CuO Nanolaminates: Effect of Stoichiometry and Layers Thickness on Energy Release and Burning Rate. Propellants, Explosives, Pyrotechnics 2014, 39 (3), 365-373. https://doi.org/10.1002/prep.201300080. 
(30) Mily, E. J.; Oni, A.; Lebeau, J. M.; Liu, Y.; Brown-Shaklee, H. J.; Ihlefeld, J. F.; Maria, J.P. The Role of Terminal Oxide Structure and Properties in Nanothermite Reactions. THIN SOLID FILMS 2014, 562, 405-410. https://doi.org/10.1016/j.tsf.2014.05.005.

(31) Marín, L.; Nanayakkara, C. E.; Veyan, J.-F.; Warot-Fonrose, B.; Joulie, S.; Estève, A.; Tenailleau, C.; Chabal, Y. J.; Rossi, C. Enhancing the Reactivity of Al/CuO Nanolaminates by $\mathrm{Cu}$ Incorporation at the Interfaces. ACS Appl. Mater. Interfaces 2015, 7 (22), 1171311718. https://doi.org/10.1021/acsami.5b02653.

(32) Kinsey, A. H.; Slusarski, K.; Sosa, S.; Weihs, T. P. Gas Suppression via Copper Interlayers in Magnetron Sputtered Al-Cu 2 O Multilayers. ACS Appl. Mater. Interfaces 2017, 9 (26), 22026-22036. https://doi.org/10.1021/acsami.7b03071.

(33) Marín, L.; Gao, Y.; Vallet, M.; Abdallah, I.; Warot-Fonrose, B.; Tenailleau, C.; Lucero, A. T.; Kim, J.; Esteve, A.; Chabal, Y. J.; Rossi, C. Performance Enhancement via Incorporation of $\mathrm{ZnO}$ Nanolayers in Energetic Al/CuO Multilayers. Langmuir 2017, 33 (41), 1108611093. https://doi.org/10.1021/acs.langmuir.7b02964.

(34) Zapata, J.; Nicollet, A.; Julien, B.; Lahiner, G.; Esteve, A.; Rossi, C. Self-Propagating Combustion of Sputter-Deposited $\mathrm{Al} / \mathrm{CuO}$ Nanolaminates. Combustion and Flame 2019, 205, 389-396. https://doi.org/10.1016/j.combustflame.2019.04.031.

(35) Cure, J.; Assi, H.; Cocq, K.; Marìn, L.; Fajerwerg, K.; Fau, P.; Bêche, E.; Chabal, Y. J.; Estève, A.; Rossi, C. Controlled Growth and Grafting of High-Density Au Nanoparticles on Zinc Oxide Thin Films by Photo-Deposition. Langmuir 2018, 34 (5), 1932-1940. https://doi.org/10.1021/acs.langmuir.7b04105.

(36) Stoney, G. G.; Parsons, C. A. The Tension of Metallic Films Deposited by Electrolysis. Proceedings of the Royal Society of London. Series A, Containing Papers of a Mathematical and Physical Character 1909, 82 (553), 172-175. https://doi.org/10.1098/rspa.1909.0021.

(37) DeLisio, J. B.; Yi, F.; LaVan, D. A.; Zachariah, M. R. High Heating Rate Reaction Dynamics of $\mathrm{Al} / \mathrm{CuO}$ Nanolaminates by Nanocalorimetry-Coupled Time-of-Flight Mass Spectrometry. J. Phys. Chem. C 2017, 121 (5), 2771-2777. https://doi.org/10.1021/acs.jpcc.6b11114.

(38) Abdallah, I.; Zapata, J.; Lahiner, G.; Warot-Fonrose, B.; Cure, J.; Chabal, Y.; Esteve, A.; Rossi, C. Structure and Chemical Characterization at the Atomic Level of Reactions in $\mathrm{Al} / \mathrm{CuO}$ Multilayers. ACS Appl. Energy Mater. 2018, 1 (4), 1762-1770. https://doi.org/10.1021/acsaem.8b00296.

(39) Lahiner, G.; Zappata, J.; Cure, J.; Richard, N.; Djafari-Rouhani, M.; Estève, A.; Rossi, C. A Redox Reaction Model for Self-Heating and Aging Prediction of $\mathrm{Al} / \mathrm{CuO}$ Multilayers. Combustion Theory and Modelling 2019, 23 (4), 700-715. https://doi.org/10.1080/13647830.2019.1584336.

(40) Dong, X.; Fang, X.; Feng, X.; Hwang, K.-C. Diffusion and Stress Coupling Effect during Oxidation at High Temperature. Journal of the American Ceramic Society 2013, 96 (1), 44 46. https://doi.org/10.1111/jace.12105.

(41) Wang, Y.; Lany, S.; Ghanbaja, J.; Fagot-Revurat, Y.; Chen, Y. P.; Soldera, F.; Horwat, D.; Mücklich, F.; Pierson, J. F. Electronic Structures of $\mathrm{Cu} 2 \mathrm{O}, \mathrm{Cu} 4 \mathrm{O} 3$, and $\mathrm{CuO}$ : A Joint Experimental and Theoretical Study. Phys. Rev. B 2016, 94 (24), 245418. https://doi.org/10.1103/PhysRevB.94.245418.

(42) Leapman, R. D.; Grunes, L. A.; Fejes, P. L. Study of the $\$\{L\}_{-}\{23\} \$$ Edges in the $\$ 3 d \$$ Transition Metals and Their Oxides by Electron-Energy-Loss Spectroscopy with 
Comparisons to Theory. Phys. Rev. B 1982, 26 (2), 614-635. https://doi.org/10.1103/PhysRevB.26.614.

(43) Jiang, N.; Spence, J. C. H. Interpretation of Oxygen K Pre-Edge Peak in Complex Oxides. Ultramicroscopy 2006, 106 (3), 215-219. https://doi.org/10.1016/j.ultramic.2005.07.004. 